\title{
Relative Telomere Length and Cardiovascular Risk Factors
}

\author{
Moritz Koriath ${ }^{1}\left(\mathbb{D}\right.$, Christian Müller ${ }^{1,2}$, Norbert Pfeiffer ${ }^{3}$, Stefan Nickels ${ }^{3} \mathbb{D}$, Manfred Beutel ${ }^{4}$, \\ Irene Schmidtmann ${ }^{5}$, Steffen Rapp ${ }^{6,7}$, Thomas Münzel 7,8,9 ${ }^{\mathbb{D}}$, Dirk Westermann 1,2, \\ Mahir Karakas ${ }^{1,2}$, Philipp S. Wild ${ }^{7,8,10,11}$, Karl J. Lackner ${ }^{7,12}$, Stefan Blankenberg ${ }^{1,2}$ and \\ Tanja Zeller ${ }^{1,2, *}$
}

1 Clinic of General and Interventional Cardiology, University Heart Center Hamburg-Eppendorf, 20246 Hamburg, Germany; m.koriath@uke.de (M.K.); Christian_m@gmx.net (C.M.); d.westermann@uke.de (D.W.); m.karakas@uke.de (M.K.); s.blankenberg@uke.de (S.B.)

2 DZHK (German Center for Cardiovascular Research), Partner Site Hamburg/Kiel/Lübeck, 20246 Hamburg, Germany

3 Department of Ophthalmology, University Medical Center of the Johannes Gutenberg-University Mainz, 55131 Mainz, Germany; norbert.pfeiffer@unimedizin-mainz.de (N.P.);

Stefan.Nickels@unimedizin-mainz.de (S.N.)

4 Department of Psychosomatic Medicine and Psychotherapy, University Medical Center of the Johannes Gutenberg-University Mainz, 55131 Mainz, Germany; Manfred.Beutel@unimedizin-mainz.de

5 Institute for Medical Biostatistics, Epidemiology and Informatics, Johannes Gutenberg-University Mainz, 55131 Mainz, Germany; irene.schmidtmann@unimedizin-mainz.de

6 Institute for Molecular Genetics, Johannes Gutenberg University, 55131 Mainz, Germany; Steffen.Rapp@unimedizin-mainz.de

7 DZHK (German Center for Cardiovascular Research), Partner Site Rhine-Main, 55131 Mainz, Germany; tmuenzel@uni-mainz.de (T.M.); philipp.wild@unimedizin-mainz.de (P.S.W.);

karl.lackner@unimedizin-mainz.de (K.J.L.)

8 Center for Cardiology-Cardiology I, University Medical Center of the Johannes Gutenberg-University Mainz, 55131 Mainz, Germany

9 Center for Translational Vascular Biology (CTVB), University Medical Center of the Johannes Gutenberg-University Mainz, 55131 Mainz, Germany

10 Preventive Cardiology and Preventive Medicine, Center for Cardiology, University Medical Center of the Johannes Gutenberg-University Mainz, 55131 Mainz, Germany

11 Center for Thrombosis and Hemostasis, University Medical Center of the Johannes Gutenberg-University Mainz, 55131 Mainz, Germany

12 Department of Clinical Chemistry and Laboratory Medicine, University Medical Center of the Johannes Gutenberg-University Mainz, 55131 Mainz, Germany

* Correspondence: t.zeller@uke.de; Tel.: +49-40-7410-56575

Received: 6 April 2019; Accepted: 15 May 2019; Published: 17 May 2019

\begin{abstract}
Background: Telomeres are repetitive DNA sequences located at the extremities of chromosomes that maintain genetic stability. Telomere biology is relevant to several human disorders and diseases, specifically cardiovascular disease. To better understand the link between cardiovascular disease and telomere length, we studied the effect of relative telomere length (RTL) on cardiovascular risk factors in a large population-based sample. (2) Methods: RTL was measured by a real-time quantitative polymerase chain reaction in subjects of the population-based Gutenberg Health Study $(n=4944)$. We then performed an association study of RTL with known cardiovascular risk factors of smoking status as well as systolic and diastolic blood pressure, body mass index (BMI), LDL cholesterol, HDL cholesterol, and triglycerides. (3) Results: A significant correlation was shown for RTL, with age as a quality control in our study (effect $=-0.004, p=3.2 \times 10^{-47}$ ). Analysis of the relation between RTL and cardiovascular risk factors showed a significant association of RTL in patients who were current smokers (effect $=-0.016, p=0.048$ ). No significant associations with RTL
\end{abstract}


were seen for cardiovascular risk factors of LDL cholesterol $(p=0.127)$, HDL cholesterol $(p=0.713)$, triglycerides $(p=0.359)$, smoking $(p=0.328)$, diastolic blood pressure $(p=0.615)$, systolic blood pressure $(p=0.949)$, or BMI $(p=0.903)$. In a subsequent analysis, we calculated the tertiles of RTL. No significant difference across RTL tertiles was detectable for BMI, blood pressure, lipid levels, or smoking status. Finally, we studied the association of RTL and cardiovascular risk factors stratified by tertiles of age. We found a significant association of RTL and LDL cholesterol in the oldest tertile of age (effect $=0.0004, p=0.006$ ). (4) Conclusions: We determined the association of relative telomere length and cardiovascular risk factors in a population setting. An association of telomere length with age, current smoking status, as well as with LDL cholesterol in the oldest tertile of age was found, whereas no associations were observed between telomere length and triglycerides, HDL cholesterol, blood pressure, or BMI.

Keywords: cardiovascular risk factors; cardiovascular disease; telomeres; telomere length; ageing

\section{Introduction}

Telomeres are special structures at the ends of chromosomes. They function as a chromosome-capping mechanism that protects the chromosomes from degradation. Telomeres maintain genomic stability through fusion and prevent cellular senescence or apoptosis. The structure of a telomere comprises repetitive, non-coding DNA sequences and specific protein complexes. Telomere length (TL) decreases with age, and leukocyte telomere length shortening is accelerated by inflammatory responses, oxidative stress, and abnormal cellular senescence [1-6]. In patients of advanced age, a correlation of telomere length has been found, amongst others, with cancer [7-9], diabetes [10], and cardiovascular disease (CVD) [11,12]. The association of TL with CVD was reported in different studies [11]. Here, a higher relative risk for coronary heart disease as well as cerebrovascular disease was observed in subjects with short leucocyte TL. Accordingly, in study of over 60,000 Danish individuals, shorter TL was associated with an elevated hazard ratio for ischemic heart disease [12].

However, the establishment of a link between TL and CVD, for example, by cardiovascular risk factors, remains unclear. For a better understanding of this link, the relation of TL and cardiovascular risk factors such as hypertension, smoking and lipid levels must be explored [4,13-23].

To broaden the understanding of the relation between TL and cardiovascular risk factors, we studied the effect of relative telomere length (RTL) in leucocytes on cardiovascular risk factors in a large population-based sample.

\section{Materials and Methods}

\subsection{Study Population}

The study population consisted of 4944 subjects from Gutenberg Health Study (GHS) [24]. GHS is a single-center cohort study with a prospective, observational, and community-based design. Local governmental registry offices in the city of Mainz and the district of Mainz-Bingen were used to randomize the study cohort. Inclusion criteria was age between 35 and 74 years. Individuals with insufficient German language skills as well as physical or psychological inabilities to attend the scheduled study center examinations were excluded. Sample stratification was performed for sex, urban or rural residence, and age. Between 2007 and 2012, 15,010 individuals were included in the study and were seen in the study center for baseline examination. GHS was approved by the Ethics Commission of the State Chamber of Physicians of Rhineland-Palatine (reference no. 837.020.07, original vote March 22, 2007, last update October 20, 2015). Written informed consent was given by all individuals before entering GHS according to the Declaration of Helsinki. 


\subsection{Definition of Cardiovascular Risk Factors}

Cardiovascular risk factors and clinical variables were classified on the basis of computer-assisted personal interviews, laboratory examinations, blood pressure, and anthropometric measurements. Standard operation procedures were used for data assessment, which was undertaken by certified medical technical assistants.

The following definitions were used for cardiovascular risk factors. Smoking status was defined as either ever or current smoker based on self-reporting. Anthropometric measurements were performed on calibrated digital scales (Seca 862, Seca, Germany). Body mass index (BMI) was calculated as the body mass in kilograms divided by the square of the body height in meters. Medication to reduce blood pressure, an observed mean systolic blood pressure $\geq 140 \mathrm{mmHg}$ or an observed mean diastolic blood pressure $\geq 90 \mathrm{mmHg}$ was classified as hypertension. Blood pressure was measured after 5,8 , and $11 \mathrm{~min}$ of rest by an automated sphygmomanometer blood pressure meter (Omron 705CP-II, OMRON Medizintechnik Handelsgesellschaft $\mathrm{GmbH}$, Germany). The second and third standardized measurement was used for the calculation of mean values.

\subsection{Collection and Processing of Blood Samples}

Peripheral blood was collected from each participant of the GHS under fasting conditions and was processed instantly according to standard operating procedures. LDL cholesterol, HDL cholesterol, and triglycerides were measured on the day of sampling by routine methods in the central laboratory of the University Medical Center in Mainz, Germany. Genomic DNA was extracted from peripheral blood leucocytes by extraction from $9 \mathrm{ml}$ EDTA blood samples using the method of Miller [25] and stored at $-80^{\circ} \mathrm{C}$ until analyses.

\subsection{Relative Telomere Length Measurements}

Relative telomere length was measured from DNA samples extracted from peripheral blood leukocytes by polymerase chain reaction (PCR) according to the method described by Cawthon [26]. The repetitive DNA sequence of telomeres was amplified in combination with the known single copy gene 36B4. Measurements included $5 \mathrm{ng} / \mu \mathrm{L}$ genomic DNA; each PCR plate contained a quality check, non-template controls, and reference DNA aliquots. Reference DNA was used as a calibrator. Dilution of DNA samples and pipetting of diluted DNA and PCR master mix into PCR plates were performed using an automated liquid handling system (Bravo Automated Liquid Handling Platform, Agilent, USA). The experiments were performed in two batches. Experiments in batch one were performed first and were performed in duplicate on two different PCR plates. Experiments in batch two were performed in triplicate on the same PCR plate. Raw data were analyzed using linregPCR (version 2012.0, 2011, no publisher), a software designed to calculate PCR efficiencies and standardized Ct values $[27,28]$. To calculate the relative telomere length (RTL) for each DNA sample, the relative telomere to single copy gene (T/S) ratio was calculated. T/S describes the factor by which the sample differed from a reference DNA sample in its ratio of telomere repeat copy number to single copy gene copy number. The RTL was proportional to the average telomere length [26] and thus was used for further analyses. The measurements were performed on an Applied Biosystems Taqman Fast Real-Time PCR 7900 HT System (Applied Biosystems, Darmstadt, Germany). Valid RTL measurements were available for 4080 subjects.

\subsection{Statistical Analysis}

Statistical analyses were performed using R ( $\mathrm{R}$ Development Core Team, version 3.4.3, www.r-project.org/). A cutoff of a RTL $>3$ or $<0.33$ was arbitrarily chosen to identify and remove outliers. Two additional steps, based on deviation from the mean, were applied to remove outliers: (i) PCR plate-wise exclusion of samples deviating $>3 \mathrm{sd}$ from the mean RTL and (ii) Overall exclusion 
of samples deviating $>$ 3sd from the mean RTL. The workflow of our quality control is shown in Supplementary Figure S1.

RTL was adjusted for age to consider the known negative correlation of RTL with age $[29,30]$. Adjusted RTL was then used in a multivariable linear regression analysis to assess the relation of RTL to both age and cardiovascular risk factors. PCR plate and batch as possible confounders were accounted for during the analysis. The known relation of RTL and age was used as a quality control. The population was divided into three tertiles depending on their RTL. The tertiles with the longest RTL was used as a reference and compared to the other tertiles in a multivariable linear regression analysis for quantitative traits. For additional analysis, samples were divided into tertiles of age. Multivariable linear regression analysis for RTL with cardiovascular risk factors was then calculated for each tertile of age separately.

Associations with a $p$-value $\leq 0.05$ were considered significant.

\section{Results}

4,080 samples had valid RTL measurements and were available for statistical analysis. Characteristics of the study population are shown in Table 1. Out of the subjects, 48.9 percent were female. Mean body mass index (BMI) was 27.2 (standard deviation [SD]: 4.7) kg/m², mean systolic blood pressure was 133 (SD: 18) $\mathrm{mmHg}$, mean diastolic blood pressure was 83 (SD: 10) $\mathrm{mmHg}$, mean LDL cholesterol was 140.0 (SD: 36.2) mg/dL, mean HDL cholesterol was 56.5 (SD: 15.8) mg/dL, and mean triglycerides were 126.2 (SD: 74.4) $\mathrm{mg} / \mathrm{dL}$.

Table 1. Baseline characteristics of the population studied. Continuous variables are shown as mean values (standard deviation), and categorical variables are shown as numbers (\%).

\begin{tabular}{cc}
\hline $\mathrm{N}$ & 4080 \\
Age, years & $55.7(10.9)$ \\
Females & $1997(48.9)$ \\
BMI, kg/m ${ }^{2}$ & $27.2(4.7)$ \\
Systolic blood pressure, $\mathrm{mmHg}$ & $132.9(17.7)$ \\
Diastolic blood pressure, $\mathrm{mmHg}$ & $83.2(9.5)$ \\
LDL-cholesterol, $\mathrm{mg} / \mathrm{dL}$ & $140.0(36.2)$ \\
HDL-cholesterol, mg/dL & $56.5(15.8)$ \\
Triglycerides, mg/dL & $126.2(74.4)$ \\
Ever smoker & $2148(53.3)$ \\
Current smoker & $764(18.8)$ \\
\hline
\end{tabular}

A significant correlation was shown for RTL with age as a quality control in our study (effect $=-0.004,95 \%$ confidence interval (CI) $\left.(-0.005-0.004), p=3.2 \times 10^{-47}\right)$ (Figure 1). Analysis of the relation between RTL and cardiovascular risk factors showed a significant association of RTL with current smoking (effect $=-0.016, \mathrm{CI}(-0.031-0.000), p=0.048)$ (Table 2). After correction for multiple testing, the effect did not remain significant (false discovery rate, $F D R=0.383$ ). No significant associations with RTL were seen for the other cardiovascular risk factors, namely LDL cholesterol $(p=0.127)$, HDL cholesterol ( $p=0.713)$, triglycerides $(p=0.359)$, ever smoking $(p=0.328)$, diastolic blood pressure $(p=0.615)$, systolic blood pressure $(p=0.949)$, and BMI $(p=0.903)$. 


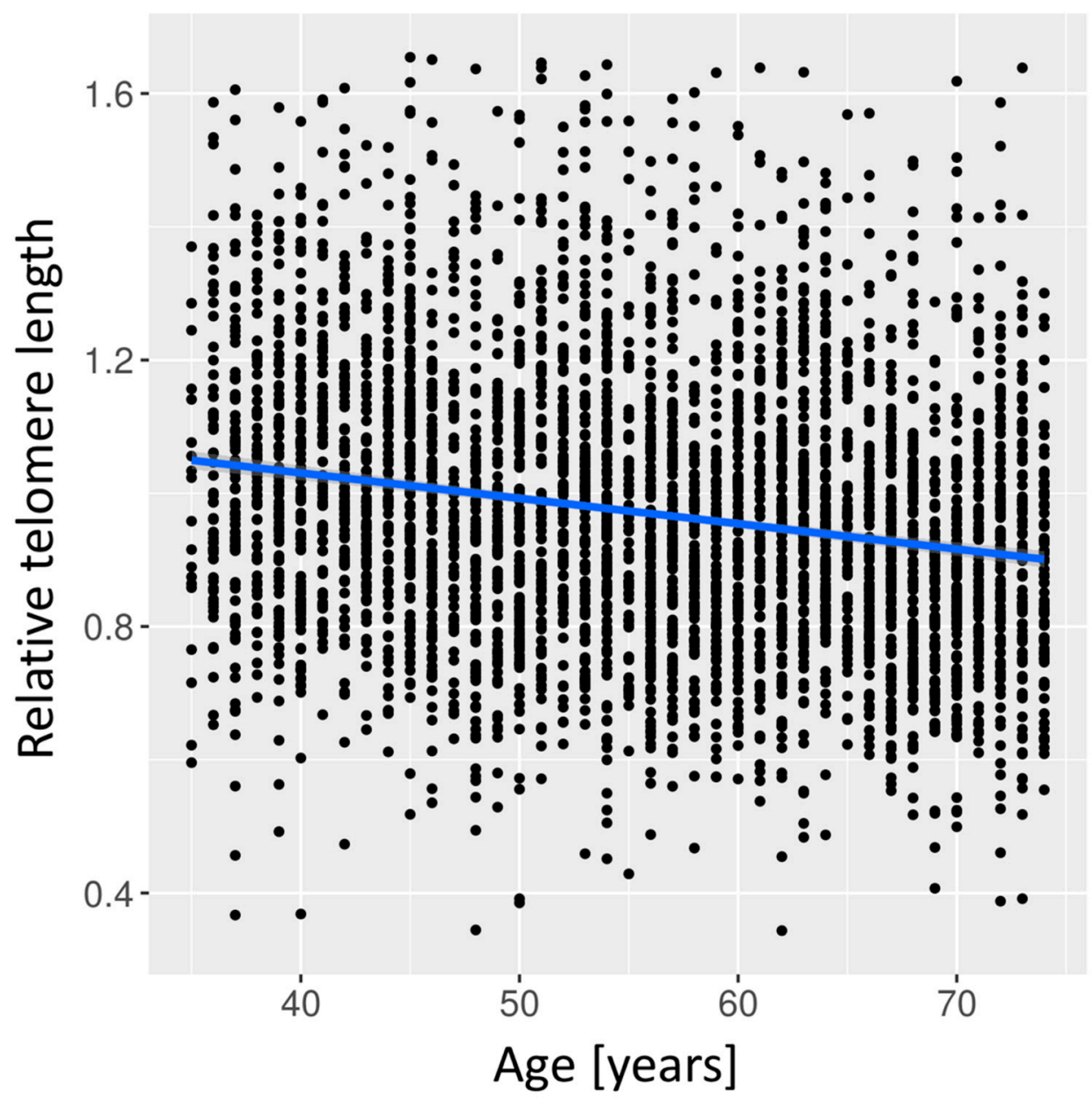

Figure 1. Correlation of relative telomere length with age. Relative telomere length was adjusted for age, batch, and PCR plate. Effect $=-0.004,95 \%$ confidence interval $(-0.005--0.004), p$-value $=3.2 \times 10^{-47}$.

Table 2. Multivariable linear regression analysis of relative telomere length on cardiovascular risk factors. Relative telomere length was adjusted for age, batch, and PCR plate.

\begin{tabular}{ccccc}
\hline Cardiovascular Risk Factor & Effect & 95\% Confidence Interval & P-Value & False Discovery Rate \\
\hline Current smoker & -0.015 & $-0.031-0.000$ & 0.048 & 0.383 \\
Ever smoker & -0.006 & $-0.018-0.006$ & 0.328 & 0.718 \\
Triglycerides & 0.000 & $0.000-0.000$ & 0.359 & 0.718 \\
LDL-cholesterol, mg/dL & 0.000 & $0.000-0.000$ & 0.127 & 0.506 \\
HDL-cholesterol, mg/dL & -0.000 & $-0.001-0.000$ & 0.713 & 0.949 \\
BMI, kg/m ${ }^{2}$ & 0.000 & $-0.001-0.001$ & 0.903 & 0.949 \\
Systolic blood pressure, $\mathrm{mmHg}$ & 0.000 & $0.000-0.000$ & 0.949 & 0.949 \\
Diastolic blood pressure, $\mathrm{mmHg}$ & 0.000 & $-0.001-0.001$ & 0.615 & 0.949 \\
\hline
\end{tabular}

Subsequently, we calculated tertiles of the RTL and compared RTL tertiles for the quantitative cardiovascular risk factors BMI, systolic and diastolic blood pressure, LDL cholesterol, HDL cholesterol, trigylcerides, and smoking status. No significant difference across RTL tertiles was detectable (Figure 2). Also, current and ever smoking showed no significant difference across RTL tertiles $(p=0.072$ for current smoking and $p=0.156$ for ever smoking). 

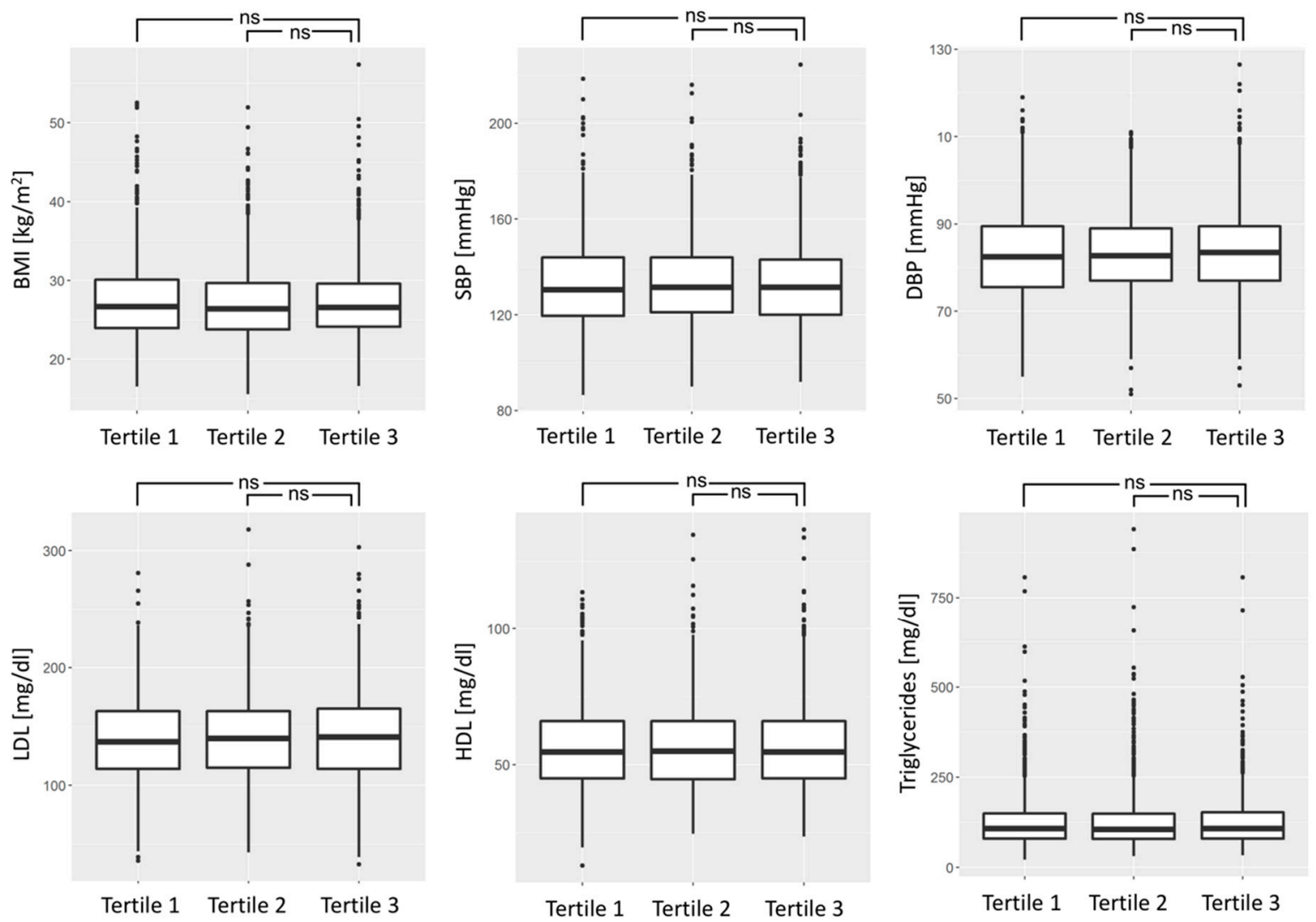

Figure 2. Relative telomere length tertiles for cardiovascular risk factors Data shown for body mass index (BMI), systolic blood pressure (SBP), diastolic blood pressure (DBP), LDL cholesterol (LDL), HDL cholesterol (HDL), and triglycerides. Tertile 1 represents shortest RTL. Differences were statistically non-significant (ns).

We also studied the association of RTL with cardiovascular risk factors according to tertiles of age. Subjects in tertile $1(n=1437)$ were between 35 and 50 years of age, in tertile $2(n=1336)$ between 51 and 62 years, and in tertile $3(n=1298)$ between 63 and 74 years. For subjects in the oldest tertile of age, a significant correlation of RTL with LDL cholesterol was found (effect $=0.0004, \mathrm{CI}(0.000-0.001)$, $p=0.006$ ) (Table 3). An association of RTL with LDL cholesterol was not seen in the other two tertiles of age (tertile $1 p=0.421$, tertile $2 p=0.900$ ). There were no significant association of RTL with other cardiovascular risk factors: BMI, systolic and diastolic blood pressure, HDL cholesterol, triglycerides, and smoking when stratified by tertiles of age. 
Table 3. Multivariable linear regression of relative telomere length on cardiovascular risk factors according to tertiles of age. Relative telomere length was adjusted for age, batch, and PCR plate.

\begin{tabular}{|c|c|c|c|c|c|c|c|c|c|c|c|c|}
\hline \multirow[b]{2}{*}{ Cardiovascular Risk Factor } & \multicolumn{4}{|c|}{ Tertile 1 ( 35 years -50 years) $n=1437$} & \multicolumn{4}{|c|}{ Tertile 2 (51 years-62 years) $n=1336$} & \multicolumn{4}{|c|}{ Tertile 3 ( 63 years- 74 years) $n=1298$} \\
\hline & Effect & $\begin{array}{l}\text { 95\% Confidence } \\
\text { Intervall }\end{array}$ & P-Value & $\begin{array}{c}\text { False discovery } \\
\text { RATE }\end{array}$ & Effect & $\begin{array}{l}\text { 95\% Confidence } \\
\text { Intervall }\end{array}$ & P-value & $\begin{array}{c}\text { False } \\
\text { Discovery Rate }\end{array}$ & Effect & $\begin{array}{l}\text { 95\% Confidence } \\
\text { Intervall }\end{array}$ & P-Value & $\begin{array}{c}\text { False } \\
\text { Discovery Rate }\end{array}$ \\
\hline Current smoker & -0.019 & $-0.042-0.004$ & 0.103 & 0.517 & -0.021 & $-0.047-0.005$ & 0.120 & 0.371 & 0.006 & $-0.030-0.042$ & 0.752 & 0.772 \\
\hline Ever smoker & -0.006 & $-0.026-0.015$ & 0.603 & 0.799 & -0.013 & $-0.034-0.009$ & 0.260 & 0.371 & 0.005 & $-0.016-0.027$ & 0.617 & 0.772 \\
\hline Triglycerides & 0.000 & $0.000-0.000$ & 0.058 & 0.517 & 0.000 & $0.000-0.000$ & 0.106 & 0.371 & 0.000 & $0.000-0.000$ & 0.323 & 0.656 \\
\hline LDL-cholesterol, mg/dL & 0.000 & $0.000-0.000$ & 0.421 & 0.799 & 0.000 & $0.000-0.000$ & 0.898 & 0.898 & 0.0004 & $0.000-0.001$ & 0.006 & 0.058 \\
\hline HDL-cholesterol, $\mathrm{mg} / \mathrm{dL}$ & 0.001 & $0.000-0.001$ & 0.186 & 0.619 & -0.001 & $-0.001-0.000$ & 0.205 & 0.371 & 0.000 & $-0.001-0.001$ & 0.638 & 0.772 \\
\hline BMI, $\mathrm{kg} / \mathrm{m}^{2}$ & -0.001 & $-0.003-0.002$ & 0.573 & 0.799 & 0.002 & $-0.001-0.004$ & 0.165 & 0.371 & -0.002 & $-0.004-0.001$ & 0.154 & 0.512 \\
\hline Systolic blood pressure, $\mathrm{mmHg}$ & 0.000 & $-0.001-0.001$ & 0.880 & 0.880 & 0.000 & $-0.001-0.001$ & 0.558 & 0.697 & 0.000 & $-0.001-0.000$ & 0.394 & 0.656 \\
\hline Diastolic blood pressure, $\mathrm{mmHg}$ & 0.000 & $-0.001-0.002$ & 0.639 & 0.799 & 0.000 & $-0.001-0.001$ & 0.843 & 0.898 & 0.000 & $-0.001-0.001$ & 0.772 & 0.772 \\
\hline
\end{tabular}




\section{Discussion}

To gain a better understanding of the link between telomere length (TL) and cardiovascular disease (CVD), we conducted an association study of relative telomere length (RTL) with cardiovascular risk factors of BMI, blood pressure, lipid levels, and smoking status in a large sample of the general population. To our knowledge, no association study for cardiovascular risk factors of this size has been undertaken in the German population to date.

Our primary results showed (i) a strong correlation of RTL with age, (ii) a modest association of RTL with current smoking status and no significant associations of RTL with lipid levels, blood pressure or BMI, (iii) no significant association of RTL with cardiovascular risk factors when analyzing tertiles of RTL, and (iv) a modest association of RTL with LDL cholesterol in the oldest tertile of age.

There have been conflicting results in smaller sample size studies regarding the relation of TL and cardiovascular risk factors $[4,13,14,16,18,19,22,23]$. Some studies have reported similar results, including an association of TL and smoking in women [17] and older men [21] but not in blood donors [15]. The relation of smoking and TL was also analyzed in a large-scale population based study by the National Health and Nutrition Examination Surveys for 1999 to 2002 (NHANES) [31]. In this study, no significant association of TL and smoking was found. However, the NHANES data set was extensively analyzed with different scopes by several study groups. Results involving TL and cardiovascular risk factors were conflicting, suggesting that the reported associations might not to be robustly reproducible [32-35].

An association of smoking and TL was also shown in a large-scale study in the Danish population [36]. However, in comparison with our study, the analyses in this Danish study found associations among TL and total cholesterol, triglycerides, and BMI [36]. A possible explanation of these differences relate to the methodological nature of the study, as the Danish study did not analyze TL as a continuous variable as we did, indicating the need to keep statistical methods in mind when comparing differing study results.

The modest association of RTL with current smoking status which we found in our initial analysis could neither be replicated in our analysis of RTL tertiles nor in our age-stratified analysis. This is possibly due to reduced statistical power when dividing the data into tertiles.

Taken together, our data provides evidence that the known association of telomere length and CVD is possibly not mediated through a strong effect of telomere length on cardiovascular risk factors.

Some limitations of our study merit consideration. We were not able to detect possible effects that might evolve over time because no longitudinal data on RTL are available. Additionally, the study population used in this study had a maximum age limit of 74 years of age. Older subjects might indicate a stronger effect of TL on cardiovascular risk factors than did our study population. Our additional finding of a modest association of RTL with LDL cholesterol in the oldest tertile of age points in this direction. Furthermore, automated assays might reduce variability of TL measurements. However, such assays were not available when we started our study. Finally, a causative effect of RTL and CVD could not be investigated because of the observational design of our study.

\section{Conclusions}

In a population setting, we determined the association between relative telomere length and cardiovascular risk factors. An association of RTL with age, current smoking status, as well as with LDL cholesterol in the oldest tertile of age was found; in contrast, no associations were observed between RTL and triglycerides, HDL cholesterol, blood pressure, or BMI. The results suggest that the known association of telomere length and CVD is not likely to be mediated through a strong effect of telomere length on cardiovascular risk factors. 
Supplementary Materials: The following is available online at http://www.mdpi.com/2218-273X/9/5/192/s1, Figure S1: Data workflow from qPCR measurements to population taken forward to statistical analysis

Author Contributions: Conceptualization M.K. (Moritz Koriath), T.Z., Methodology M.K. (Moritz Koriath), C.M., T.Z., Analysis C.M., Investigation M.K. (Moritz Koriath), Resources I.S., S.R., P.S.W. Writing-Original Draft Preparation M.K. (Moritz Koriath), T.Z., Writing-Review and Editing M.K. (Moritz Koriath), C.M., N.P., S.N., M.B., I.S., S.R., T.M., D.W., M.K. (Mahir Karakas), P.S.W., K.L., S.B., T.Z., Supervision T.Z., S.B., Funding Acquisition S.B., P.S.W., T.Z

Funding: The Gutenberg Health Study is funded through the government of Rhineland-Palatine ("Stiftung Rheinland-Pfalz für Innovation", contract AZ 961-386261/733), the research programs "Wissen schafft Zukunft" and "Center for Translational Vascular Biology (CTVB)" of the Johannes Gutenberg University of Mainz, and its contract with Boehringer Ingelheim, PHILIPS Medical Systems and Novartis Pharma, including an unrestricted grant for the Gutenberg Health Study. This work has been supported by the German Center for Cardiovascular Research (DZHK e.V.), [81Z1710101 to TZ] and by the European Research Area Network (ERA-Net) (PREMED-CAD). The funders had no role in study design, data collection and analysis, decision to publish, or preparation of the manuscript.

Acknowledgments: We are indebted to all study participants who took part in this study as well as to the coworkers of the Gutenberg Health Study who were involved in the planning and conduct of this study.

Conflicts of Interest: The authors declare no conflicts of interests.

\section{References}

1. Monaghan, P.; Eisenberg, D.T.A.; Harrington, L.; Nussey, D. Understanding diversity in telomere dynamics. Philos. Trans. R. Soc. 2018, 373, 1741. [CrossRef] [PubMed]

2. Chan, S.R.; Blackburn, E.H. Telomeres and telomerase. Philos. Trans. of the R. Soc. B 2004, 359, $109-121$. [CrossRef] [PubMed]

3. Blackburn, E.H.; Epel, E.S.; Lin, J. Human telomere biology: A contributory and interactive factor in aging, disease risks, and protection. Science 2015, 350, 1193-1198. [CrossRef]

4. Demissie, S.; Levy, D.; Benjamin, E.J.; Cupples, L.A.; Gardner, J.P.; Herbert, A.; Kimura, M.; Larson, M.G.; Meigs, J.B.; Keaney, J.F.; et al. Insulin resistance, oxidative stress, hypertension, and leukocyte telomere length in men from the framingham heart study. Aging Cell 2006, 5, 325-330. [CrossRef]

5. Von Zglinicki, T. Oxidative stress shortens telomeres. Trends Biochem. Sci. 2002, 27, 339-344. [CrossRef]

6. Zee, R.Y.; Ridker, P.M.; Chasman, D.I. Genetic variants in eleven telomere-associated genes and the risk of incident cardio/cerebrovascular disease: The Women's Genome Health Study. Clin. Chim. Acta 2011, 412, 199-202. [CrossRef]

7. Wentzensen, I.M.; Mirabello, L.; Pfeiffer, R.M.; Savage, S.A. The association of telomere length and cancer: A meta-analysis. Cancer Epidemiol. Biomark. Prev. 2011, 20, 1238-1250. [CrossRef]

8. Ma, H.; Zhou, Z.; Wei, S.; Liu, Z.; Pooley, K.A.; Dunning, A.M.; Svenson, U.; Roos, G.; Hosgood, H.D., 3rd; Shen, M.; et al. Shortened telomere length is associated with increased risk of cancer: A meta-analysis. PLOS ONE 2011, 6, e20466. [CrossRef]

9. Zhang, X.; Zhao, Q.; Zhu, W.; Liu, T.; Xie, S.H.; Zhong, L.X.; Cai, Y.Y.; Li, X.N.; Liang, M.; Chen, W.; et al. The association of telomere length in peripheral blood cells with cancer risk: A systematic review and meta-analysis of prospective studies. Cancer Epidemiol. Biomark. Prev. 2017, 26, 1381-1390. [CrossRef]

10. Zhao, J.; Miao, K.; Wang, H.; Ding, H.; Wang, D.W. Association between telomere length and type 2 diabetes mellitus: A meta-analysis. PLoS ONE 2013, 8, e79993. [CrossRef] [PubMed]

11. Haycock, P.C.; Heydon, E.E.; Kaptoge, S.; Butterworth, A.S.; Thompson, A.; Willeit, P. Leucocyte telomere length and risk of cardiovascular disease: Systematic review and meta-analysis. BMJ 2014, 349, g4227. [CrossRef] [PubMed]

12. Scheller Madrid, A.; Rode, L.; Nordestgaard, B.G.; Bojesen, S.E. Short telomere length and ischemic heart disease: Observational and genetic studies in 290022 individuals. Clin. Chem. 2016, 62, 1140-1149. [CrossRef]

13. Fitzpatrick, A.L.; Kronmal, R.A.; Gardner, J.P.; Psaty, B.M.; Jenny, N.S.; Tracy, R.P.; Walston, J.; Kimura, M.; Aviv, A. Leukocyte telomere length and cardiovascular disease in the cardiovascular health study. Am. J. Epidemiol. 2007, 165, 14-21. [CrossRef] [PubMed]

14. Jiang, X.; Dong, M.; Cheng, J.; Huang, S.; He, Y.; Ma, K.; Tang, B.; Guo, Y. Decreased leukocyte telomere length (ltl) is associated with stroke but unlikely to be causative. PLoS ONE 2013, 8, e68254. [CrossRef] 
15. Neuner, B.; Lenfers, A.; Kelsch, R.; Jager, K.; Bruggmann, N.; van der Harst, P.; Walter, M. Telomere length is not related to established cardiovascular risk factors but does correlate with red and white blood cell counts in a german blood donor population. PLoS ONE 2015, 10, e0139308. [CrossRef] [PubMed]

16. Zhang, W.G.; Zhu, S.Y.; Zhao, D.L.; Jiang, S.M.; Li, J.; Li, Z.X.; Fu, B.; Zhang, M.; Li, D.G.; Bai, X.J.; et al. The correlation between peripheral leukocyte telomere length and indicators of cardiovascular aging. Heart Lung Circ. 2014, 23, 883-890. [CrossRef]

17. Valdes, A.M.; Andrew, T.; Gardner, J.P.; Kimura, M.; Oelsner, E.; Cherkas, L.F.; Aviv, A.; Spector, T.D. Obesity, cigarette smoking, and telomere length in women. Lancet 2005, 366, 662-664. [CrossRef]

18. Wulaningsih, W.; Kuh, D.; Wong, A.; Hardy, R. Adiposity, telomere length and telomere attrition in midlife: The 1946 british birth cohort. J. Gerontol. Series A Biol. Sci. Med. Sci. 2017. [CrossRef]

19. Strandberg, T.E.; Saijonmaa, O.; Fyhrquist, F.; Tilvis, R.S.; Strandberg, A.Y.; Miettinen, T.A.; Pitkala, K.H.; Salomaa, V. Telomere length in old age and cholesterol across the life course. J. Am. Geriatr. Soc. 2011, 59, 1979-1981. [CrossRef] [PubMed]

20. Muezzinler, A.; Zaineddin, A.K.; Brenner, H. Body mass index and leukocyte telomere length in adults: A systematic review and meta-analysis. Obes. Rev. 2014, 15, 192-201. [CrossRef]

21. Strandberg, T.E.; Saijonmaa, O.; Tilvis, R.S.; Pitkala, K.H.; Strandberg, A.Y.; Miettinen, T.A.; Fyhrquist, F. Association of telomere length in older men with mortality and midlife body mass index and smoking. J. Gerontol. Series A Biol. Sci. Med. Sci. 2011, 66, 815-820. [CrossRef] [PubMed]

22. Willeit, P.; Willeit, J.; Brandstatter, A.; Ehrlenbach, S.; Mayr, A.; Gasperi, A.; Weger, S.; Oberhollenzer, F.; Reindl, M.; Kronenberg, F.; et al. Cellular aging reflected by leukocyte telomere length predicts advanced atherosclerosis and cardiovascular disease risk. Arterioscler. Thromb. Vasc. Biol. 2010, 30, 1649-1656. [CrossRef]

23. Bekaert, S.; De Meyer, T.; Rietzschel, E.R.; De Buyzere, M.L.; De Bacquer, D.; Langlois, M.; Segers, P.; Cooman, L.; Van Damme, P.; Cassiman, P.; et al. Telomere length and cardiovascular risk factors in a middle-aged population free of overt cardiovascular disease. Aging Cell 2007, 6, 639-647. [CrossRef]

24. Wild, P.S.; Zeller, T.; Beutel, M.; Blettner, M.; Dugi, K.A.; Lackner, K.J.; Pfeiffer, N.; Munzel, T.; Blankenberg, S. The Gutenberg Health Study. Bundesgesundheitsblatt Gesundh. Gesundh. 2012, 55, 824-849. [CrossRef]

25. Miller, S.A.; Dykes, D.D.; Polesky, H.F. A simple salting out procedure for extracting DNA from human nucleated cells. Nucleic Acids Res. 1988, 16, 1215. [CrossRef] [PubMed]

26. Cawthon, R.M. Telomere measurement by quantitative pcr. Nucleic Acids Res. 2002, 30, e47. [CrossRef] [PubMed]

27. Ruijter, J.M.; Ramakers, C.; Hoogaars, W.M.; Karlen, Y.; Bakker, O.; van den Hoff, M.J.; Moorman, A.F. Amplification efficiency: Linking baseline and bias in the analysis of quantitative pcr data. Nucleic Acids Res. 2009, 37, e45. [CrossRef] [PubMed]

28. Ramakers, C.; Ruijter, J.M.; Deprez, R.H.; Moorman, A.F. Assumption-free analysis of quantitative real-time polymerase chain reaction (pcr) data. Neurosci. Lett. 2003, 339, 62-66. [CrossRef]

29. Hastie, N.D.; Dempster, M.; Dunlop, M.G.; Thompson, A.M.; Green, D.K.; Allshire, R.C. Telomere reduction in human colorectal carcinoma and with ageing. Nature 1990, 346, 866-868. [CrossRef]

30. Harley, C.B.; Futcher, A.B.; Greider, C.W. Telomeres shorten during ageing of human fibroblasts. Nature 1990, 345, 458-460. [CrossRef] [PubMed]

31. Steward, A.M.; Morgan, J.D.; Espinosa, J.P.; Turk, D.C.; Patel, K.V. Chronic pain and telomere length in community-dwelling adults: Findings from the 1999 to 2002 national health and nutrition examination survey. J. Pain 2017, 18, 1517-1525. [CrossRef] [PubMed]

32. Batsis, J.A.; Mackenzie, T.A.; Vasquez, E.; Germain, C.M.; Emeny, R.T.; Rippberger, P.; Lopez-Jimenez, F.; Bartels, S.J. Association of adiposity, telomere length and mortality: Data from the nhanes 1999-2002. Int. J. Obes. 2018, 42, 198-204. [CrossRef] [PubMed]

33. Cheng, Y.Y.; Kao, T.W.; Chang, Y.W.; Wu, C.J.; Peng, T.C.; Wu, L.W.; Yang, H.F.; Liaw, F.Y.; Chen, W.L. Examining the gender difference in the association between metabolic syndrome and the mean leukocyte telomere length. PLoS ONE 2017, 12, e0180687. [CrossRef] [PubMed]

34. Mazidi, M.; Kengne, A.P.; Sahebkar, A.; Banach, M. Telomere length is associated with cardiometabolic factors in us adults. Angiology 2018, 69, 164-169. [CrossRef] 
35. Rehkopf, D.H.; Needham, B.L.; Lin, J.; Blackburn, E.H.; Zota, A.R.; Wojcicki, J.M.; Epel, E.S. Leukocyte telomere length in relation to 17 biomarkers of cardiovascular disease risk: A cross-sectional study of us adults. PLoS Med. 2016, 13, e1002188. [CrossRef] [PubMed]

36. Weischer, M.; Bojesen, S.E.; Cawthon, R.M.; Freiberg, J.J.; Tybjaerg-Hansen, A.; Nordestgaard, B.G. Short telomere length, myocardial infarction, ischemic heart disease, and early death. Arterioscler. Thromb. Vasc. Biol. 2012, 32, 822-829. [CrossRef] [PubMed]

(C) 2019 by the authors. Licensee MDPI, Basel, Switzerland. This article is an open access article distributed under the terms and conditions of the Creative Commons Attribution (CC BY) license (http://creativecommons.org/licenses/by/4.0/). 